\title{
Microstructural characterization of apple tissue during drying using X-Ray microtomography
}

\author{
Rahman M. M. a , Billah, M. M. ${ }^{\text {, }}$ Khan, M.I.H. ${ }^{\text {, }}$ Karim, M.A ${ }^{a^{*}}$ \\ a School of Chemistry Physic and Mechanical Engineering, Science and Engineering Faculty, \\ Queensland University of Technology, Australia \\ b Department of Arts and Sciences, Ahsanullah University of Science and Technology, Dhaka-1208, \\ Bangladesh
}

*E-mail of the corresponding author: azharul.karim@qut.edu.au

\begin{abstract}
This study aims to investigate the complex microstructural changes in plantbased food materials during drying by using X-ray micro-computed tomography $(X$-ray $\mu C T)$ along with the image analysis. The apple samples were dried at $60^{\circ} \mathrm{C}$ and tested using $X$-ray $\mu C T$ at different stages of drying. The porosity, cell and pore size distribution were determined from the microCT data set. It was observed that significant changes in porosity, cell and pore size distribution take place at different drying times and moisture contents. $X$ ray $\mu C T$ can serve as a very promising tool to elucidate the evolution of the food microstructure during the drying process.
\end{abstract}

Keywords: Food drying, characteristics, X-ray microtomography, nondestructive evaluation. 


\section{Introduction}

Drying of fruits and vegetables is a complex process as their structures are heterogeneous and changes in microstructures significantly affect the drying process ${ }^{1-3}$. Plant-based food material consists of cells and intercellular spaces. The major component of plant-based food materials is the water which is distributed in the cells and intercellular spaces ${ }^{4-5}$. Therefore, it is crucial to understand the evolution of microstructural characteristics to make an accurate prediction of energy requirement and the physical quality during drying of plant-based food material.

There are several methods such as Scanning electron microscope, light microscope, X-ray microtomography reported in the literature for the investigation of cellular structure in the fresh food sample ${ }^{6-7}$. However, very limited research has been conducted to investigate the evolution of the microstructural characteristics during drying of food material. The researchers have anticipated the cell breakdown under certain drying condition ${ }^{8-9}$. Cell collapse depends on internal thermal stress that first develops near the surface and gradually penetrates to the center of the sample during convective drying ${ }^{8}$. In other words, entire food sample does not reach breakdown temperature at a time. Therefore, it is critical to investigate the evolution of the cellular level structure during the drying process.

The proper microstructural information regarding the changes of cellular structure and porosity of the plant-based food is required to improve the physical quality of the dried food 10. Most of the microstructural investigation techniques used by the researchers are destructive and invasive ${ }^{11-13}$. Therefore, these methods are not suitable for the structural characterization of the plant-based food material during drying ${ }^{14-15}$. The limitations of the destructive and the invasive methods justify the importance of high resolution nondestructive and non-invasive methods. There is a major gap in the literature regarding the application of the non-invasive method to investigate the micro level structural changes during drying of food material ${ }^{14}$. Hence, the evolution of microstructural characteristics during the drying process is still not clear to the food engineers. To address this research gap, $\mathrm{X}$-ray $\mu \mathrm{CT}$ can be a very useful technique to elucidate the cellular level structural changes during food drying ${ }^{16}$. Therefore, the main aim of this work is to experimentally investigate the change in microstructural characteristics (Cells and pore size distributions) during drying of apple tissue.

\section{Materials and Methods}

\subsection{Sample preparation and the drying experiment}

Drying was carried out in a laboratory-scale temperature-controlled convective dryer. Granny Smith apple was taken as a sample for this experiment. The fresh apples were collected from the local market and stored in a refrigerator at $4{ }^{\circ} \mathrm{C}$ to keep them fresh before the drying 
experiment. Prior to the drying test, the samples were taken out from the refrigerator and kept at the room temperature for an hour for achieving thermal stability of the sample. The samples were then washed and cut into cylindrical slices of $10 \mathrm{~mm}$ thickness and $20 \mathrm{~mm}$ diameter. The dryer was started 30 min before of the experiment for allowing the system reaches the steady state condition. The drying experiments were performed at $60^{\circ} \mathrm{C}$ temperature. For each drying experiment; six samples were taken. During each experiment, air velocity of 0.7 $\mathrm{m} / \mathrm{s}$ and the relative humidity range between $60-65 \%$ were maintained. The moisture content of the sample at the different stage of drying was measured using X-ray microtomographic images. The details of the moisture content measuring technique can be found in author's previous work ${ }^{14}$.

\subsection{X-ray microtomography}

In this study, X-ray $\mu \mathrm{CT}$ was used to investigate the micro level structural changes. X-ray $\mu \mathrm{CT}$ is able to scan the entire sample to obtain micro-level information such as cell and pore size distribution without the need for serial cuts or chemical treatment. Therefore, the same sample can be used at the next stages of the drying process. To observe the micro level morphological changes, the samples were taken out from the dryer tray after every 30 min during drying. Before placing into the X-ray $\mu \mathrm{CT}$, the samples were kept in a desiccator to avoid the natural rehydration to the ambient condition of the laboratory. The apple samples were scanned using a Scanco-40 $\mu \mathrm{CT}$ high-resolution desktop $\mu$-CT system which consists of a resolution of $6 \mu \mathrm{m}$. The scanning was operated at $55 \mathrm{KV}$, and the images were taken through $0^{\circ}-180^{\circ}$ of rotation. The process is controlled by a built-in a software package which uses the back-projection algorithm. After the scanning, the samples were placed back into the dryer, and the scanning images were collected for the further investigations.

\subsection{Image processing and data analysis}

The grayscale images obtained from the X-ray $\mu \mathrm{CT}$ was transferred to MATLAB image processing environment for further processing. The image processing involved the noise elimination and segmentation. The noise elimination was performed by the intensity thresholding and the filtering process. Segmentation was performed after the noise elimination process to characterize solid materials in the microscopic images. For this purpose, Watershed algorithm was used. The area of the cells and intercellular spaces are obtained from the pixel of the X-ray tomographic images of the food material. At the different stages of drying the images were collected and the area was calculated. The change of shrinkage was estimated from the area ratio (AR) by the following relationship

$$
A R=\frac{A_{x}}{A_{0}}
$$


where, $A_{x}$ is the area of the cell/intercellular space at a different stage of drying, $A_{0}$ is the area of cell/intercellular space of fresh sample.

The porosity of the samples at different stages of drying was determined from the X-ray $\mu \mathrm{CT}$ data. The porosity was calculated by the following relationship ${ }^{17}$ :

$$
\text { Porosity }=\frac{V_{\text {Int }}}{V_{T}}
$$

where, $V_{\text {Int }}$ is the total volume of the intercellular space and $V_{T}$ is the total volume of the sample.

The area distribution of cell and intercellular space in tissue was estimated by probability density function as given below ${ }^{18}$

$$
\operatorname{Pr}(a \leq x \leq b)=\int_{a}^{b} f(x) d x
$$

where, $\mathrm{x}$ is the variable denotes the area of the cell or intercellular spaces.

\section{Result and discussion}

The structural change of food material is the result of collapse and shrinkage of the cells and cell walls during the drying period when significant loss of water takes place ${ }^{19-20}$. There is a significant difference between collapse and shrinkage. Collapse takes place when cellular or tissue level structure breaks down irreversibly; whereas shrinkage refers to a reversible reduction in the size of food material. The shrinkage of the apple tissue was measured from the tomographic image analysis. The tomographic image of the fresh apple and dried apple is presented in Figure 1. In this figure, the high-intensity region of the image represents the cellular area while the low-intensity region of the image represents the intercellular space area. The fresh tissue the cells are intact and filled with water. In the dried tissue, the cellular area shrinks due to the moisture loss. It is interesting to observe that the overall shrinkage of the sample is arbitrary. This kind of shrinkage is known as anisotropic shrinkage.

The apple tissue has the amorphous structure, and during the drying process, it shows the anisotropic shrinkage. Therefore, it is ideal to estimate the shrinkage of apple tissue in terms of area ratio. The evolution of the areal shrinkage as a function of moisture content at $60^{\circ} \mathrm{C}$ is presented in Figure 2. It is clear from the figure that the apple tissue experiences 35\% shrinkage during the drying process. This kind of shrinkage phenomena is commonly known as large deformation. Several factors are responsible for the shrinkage phenomena including the structural heterogeneity and the drying temperature. 


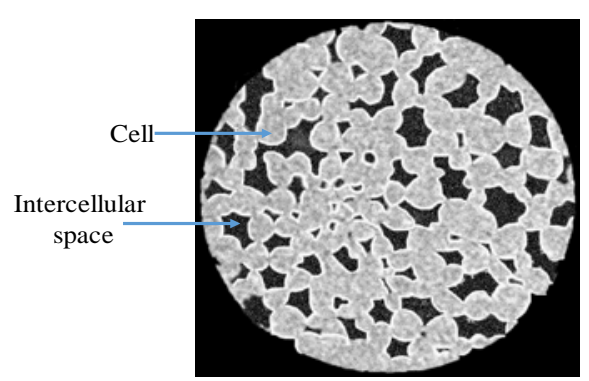

(a)

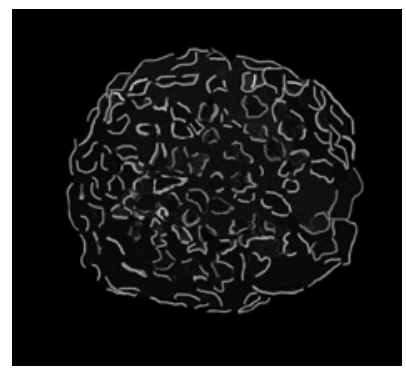

(b)

Figure 1. X-ray tomographic image of (a) fresh apple tissue and (b) dried at $60^{\circ} \mathrm{C}$ temperature

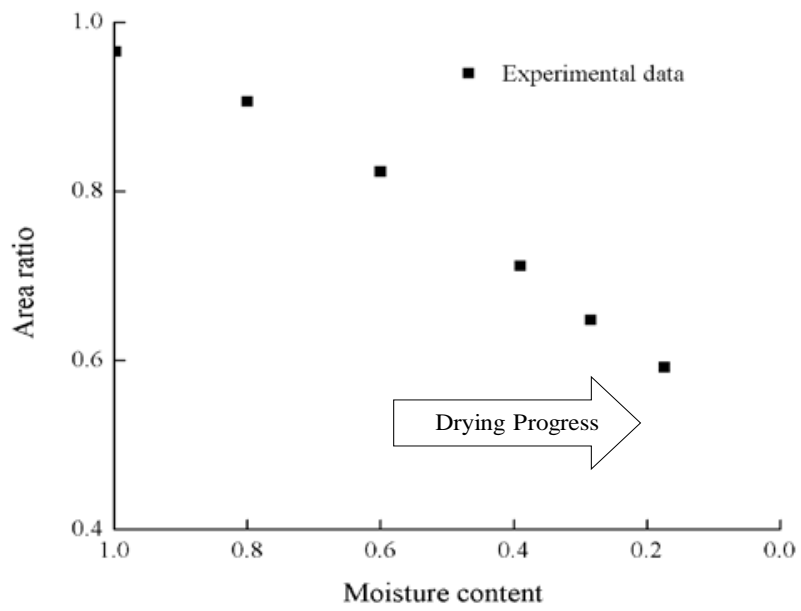

Figure 2. Evolution of areal shrinkage of apple as a function of moisture content during drying at $60^{\circ} \mathrm{C}$.

The size of cells and intercellular spaces were obtained from the tomographic image analysis. The size distribution of cells and the intercellular spaces in fresh apple tissue is presented in Figure 3. It can be seen that in fresh sample, the cellular area is distributed in a wide range. It was also observed that the cell size is bigger than the intercellular spaces.

Figure 4 represents the evolution of the area of cells and intercellular spaces during the drying process. After 60 min drying the size of the cellular area is reduced slowly while the area of the intercellular space changes rapidly (Figure 4a). This is because a negative pressure is created inside the cells due to the removal of water during the drying process. The water migration process in this stage is mainly the free water removal. Owing to ongoing moisture migration, the collapse of cells and intercellular spaces is increased at the later stages of drying. After 350 min drying time, it was found that the pore size distribution is greater than the cell size distributions (Figure 4b). 


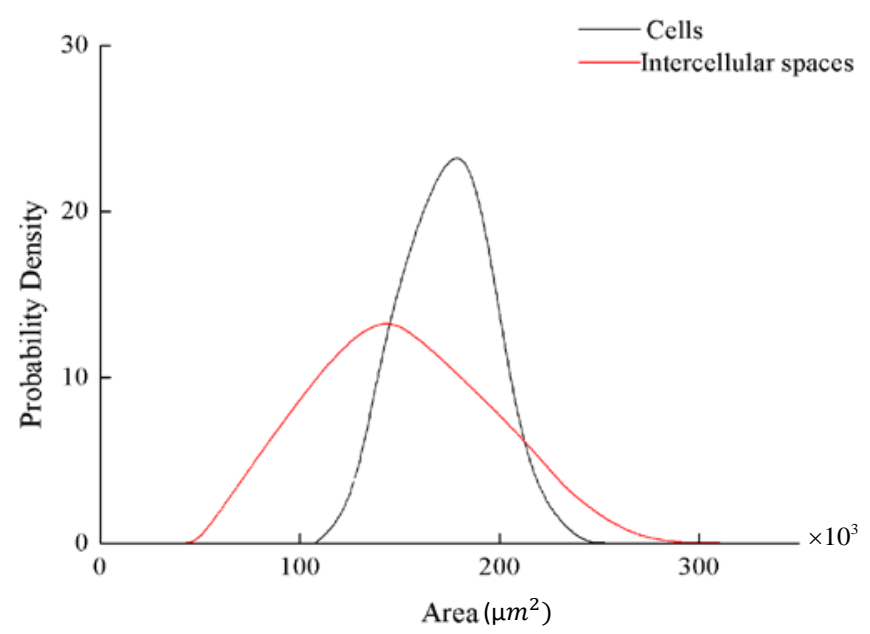

Figure 3. Areal distribution of cell and intercellular space in fresh apple tissue

The porosity of the samples was calculated from the images using equation (2). The porosity of the plant-based food materials also shows an interesting relationship with moisture content. Figure 5 shows the changes in porosity of apple sample at $60^{\circ} \mathrm{C}$ drying temperature against the moisture content. It can be seen that a decreasing trend of porosity has been found just before an inversion starts at moisture ration of 0.7 (Dry basis). This may be due to the shrinkage of initial porosity of apple at the early stage of drying ${ }^{11}$. After that, porosity keeps increasing steadily with moisture content until the end of the drying.
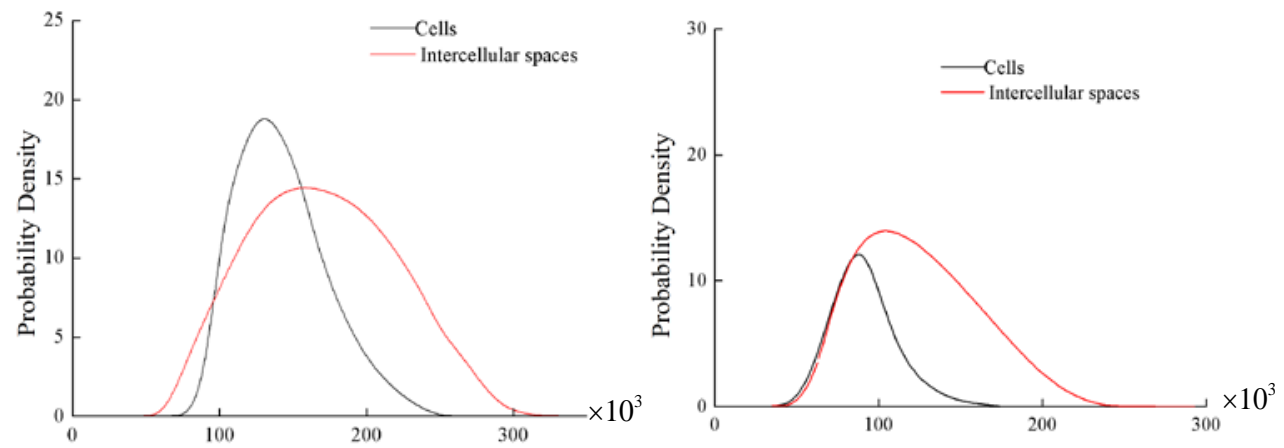

Figure 4. Areal distribution of cell and intercellular space after (a)60 min, (b) $350 \mathrm{~min}$ of drying 


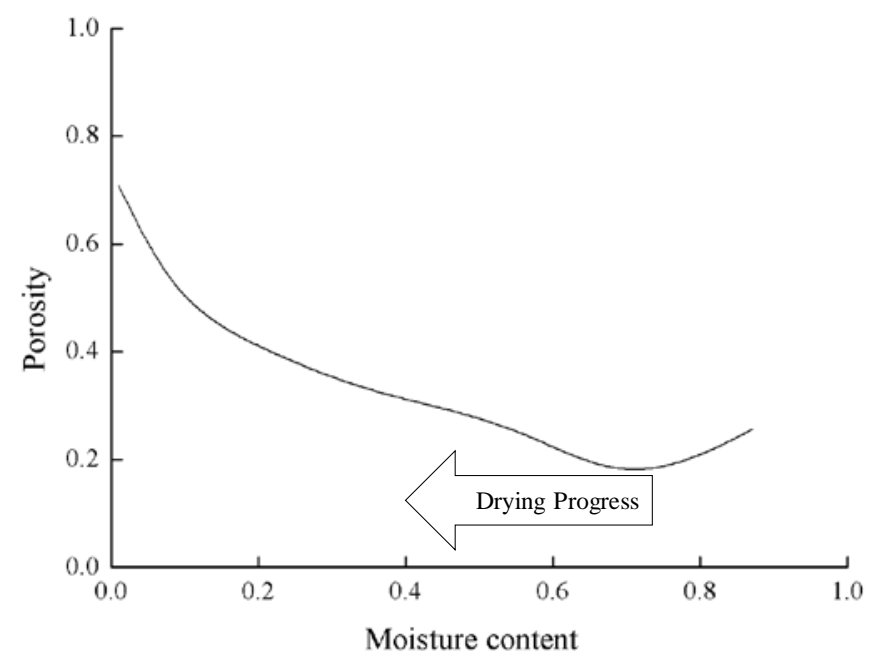

Figure 5. Evolution of porosity of apple during drying at $60^{\circ} \mathrm{C}$

\section{Conclusion}

This paper investigates the evolution of microstructural characteristics of apple samples as a function of moisture content during drying. The applicability of X-ray microtomography along with the image processing technique in the analysis of cell and intercellular space size distribution in fruits and vegetable during drying is established in this study. This technique is nondestructive and requires minimum effort in sample preparation. It has been found that the cell and the pore size distribution of the food material change significantly over the drying period. The cellular area is larger than the intercellular area in the fresh apple tissue. Nevertheless, towards the end of the drying process, a larger amount of intercellular spaces was observed, which is directly related to the porosity of the apple tissue. The quantitive information of this study will facilitate the future researchers to understand the relationship between the moisture content and the evolution of microstructure during the drying process. The findings of this investigation will help the food engineers to develop and validate accurate food drying model which will lead to the design of an efficient food drying process.

\section{Acknowledgment}

This research is supported by Queensland University of Technology Postgraduate Award (QUTPRA) and Advanced Queensland Fellowship (AQF). The authors acknowledge the facilities and the technical assistance of the Institute of Health and Biomedical Innovation (IHBI). The authors also gratefully acknowledge the support of Dr. Marie-Luise Wille. 


\section{References}

[1] Joardder, M. U.; Kumar, C.; Karim, M., Food structure: its formation and relationships with other properties. Critical reviews in food science and nutrition 2017, 57 (6), 1190-1205.

[2] Rahman, M.; Mekhilef, S.; Saidur, R.; Mustayen Billah, A.; Rahman, S., Mathematical modelling and experimental validation of solar drying of mushrooms. International Journal of Green Energy 2016, 13 (4), 344-351.

[3] Karim, M. A.; Rahman, M. M.; Pham, N. D.; Fawzia, S., Food Microstructure as affected by processing and its effect on quality and stability. In Food Microstructure and Its Relationship with Quality and Stability, Elsevier: 2017; pp 43-57.

[4] Khan, M. I. H.; Wellard, R. M.; Nagy, S. A.; Joardder, M.; Karim, M., Investigation of bound and free water in plant-based food material using NMR T 2 relaxometry. Innovative Food Science \& Emerging Technologies 2016, 38, 252-261.

[5] Kumar, C.; Joardder, M. U. H.; Farrell, T. W.; Millar, G. J.; Karim, M. A., Mathematical model for intermittent microwave convective drying of food materials. Drying Technology 2016, 34 (8), 962-973.

[6] Khan, M. I. H.; Karim, M., Cellular water distribution, transport, and its investigation methods for plant-based food material. Food Research International 2017.

[7] Joardder, M. U. H.; Brown, R. J.; Kumar, C.; Karim, M. A., Effect of Cell Wall Properties on Porosity and Shrinkage of Dried Apple. International Journal of Food Properties 2015, 18 (10), 2327-2337.

[8] Khan, M. I. H.; Wellard, R. M.; Nagy, S. A.; Joardder, M.; Karim, M., Experimental investigation of bound and free water transport process during drying of hygroscopic food material. International Journal of Thermal Sciences 2017, 117, 266-273.

[9] Rizzolo, A.; Vanoli, M.; Cortellino, G.; Spinelli, L.; Contini, D.; Herremans, E.; Bongaers, E.; Nemeth, A.; Leitner, M.; Verboven, P., Characterizing the tissue of apple air-dried and osmo-air-dried rings by X-CT and OCT and relationship with ring crispness and fruit maturity at harvest measured by TRS. Innovative Food Science \& Emerging Technologies 2014, 24, 121-130.

[10] Kumar, C.; Joardder, M. U. H.; Farrell, T. W.; Karim, M. A., Investigation of intermittent microwave convective drying (IMCD) of food materials by a coupled 3D electromagnetics and multiphase model. Drying Technology 2018, 36 (6), 736-750.

[11] Joardder, M. U.; Kumar, C.; Brown, R. J.; Karim, M., A micro-level investigation of the solid displacement method for porosity determination of dried food. Journal of Food Engineering 2015, 166, 156-164.

[12] Joardder, M. U.; Kumar, C.; Karim, M., Prediction of porosity of food materials during drying: Current challenges and future directions. Critical Reviews in Food Science and Nutrition 2017, (just-accepted).

[13] Rahman, M. M.; Joardder, M. U. H.; Khan, M. I. H.; Pham, N. D.; Karim, M. A., Multi-scale model of food drying: Current status and challenges. Critical Reviews in Food Science and Nutrition 2018, 58 (5), 858-876.

[14] Rahman, M. M.; Joardder, M. U. H.; Karim, A., Non-destructive investigation of cellular level moisture distribution and morphological changes during drying of a plant-based food material. Biosystems Engineering 2018, 169, 126-138.

[15] Khan, M. I. H.; Nagy, S. A.; Karim, M. A., Transport of cellular water during drying: An understanding of cell rupturing mechanism in apple tissue. Food Research International 2018, 105, 772-781.

[16] Rahman, M. M.; Kumar, C.; Joardder, M. U. H.; Karim, M. A., A micro-level transport model for plant-based food materials during drying. Chemical Engineering Science 2018, 187, 1-15.

[17] Joardder, M. U.; Karim, A.; Kumar, C.; Brown, R. J., Porosity: Establishing the Relationship Between Drying Parameters and Dried Food Quality. Springer: 2015.

[18] Rahman, M. M.; Gu, Y. T.; Karim, M. A., Development of realistic food microstructure considering the structural heterogeneity of cells and intercellular space. Food Structure 2018, 15, 9-16.

[19] Ramos, I. N.; Branda o, T. R. S.; Silva, C. L. M., Structural Changes During Air Drying of Fruits and Vegetables. Food Science Technology International 2003, 9 (3), 201-6.

[20] Devahastin, S.; Niamnuy, C., Modelling quality changes of fruits and vegetables during drying: a review. International Journal of Food Science and Technology 2010, 45 (9), 1755-1767. 